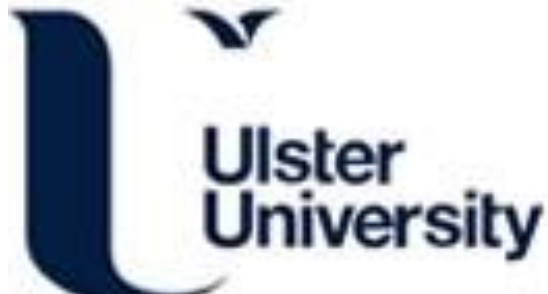

The crucial role of market intelligence in the development of small business marketing capabilities

Carson, G., O'Connor, C., \& Simmons, G. (2020). The crucial role of market intelligence in the development of small business marketing capabilities. Journal of Small Business and Enterprise Development, 27(5), 797-816. https://doi.org/10.1108/JSBED-12-2019-0394

Link to publication record in Ulster University Research Portal

Published in:

Journal of Small Business and Enterprise Development

Publication Status:

Published (in print/issue): 19/06/2020

DOI:

10.1108/JSBED-12-2019-0394

Document Version

Author Accepted version

\section{General rights}

Copyright for the publications made accessible via Ulster University's Research Portal is retained by the author(s) and / or other copyright owners and it is a condition of accessing these publications that users recognise and abide by the legal requirements associated with these rights.

\section{Take down policy}

The Research Portal is Ulster University's institutional repository that provides access to Ulster's research outputs. Every effort has been made to ensure that content in the Research Portal does not infringe any person's rights, or applicable UK laws. If you discover content in the Research Portal that you believe breaches copyright or violates any law, please contact pure-support@ulster.ac.uk. 
'This author accepted manuscript is deposited under a Creative Commons Attribution Non-commercial 4.0 International

(CC BY-NC) licence. This means that anyone may distribute, adapt, and build upon the work for non-commercial purposes, subject to full attribution. If you wish to use this manuscript for commercial purposes, please contact permissions@emerald.com.'

\title{
The crucial role of market intelligence in the development of small business marketing capabilities
}

\author{
Grace Carson \\ Queen's Management School, Queen's University Belfast, Belfast, UK \\ Christina O'Connor \\ School of Business, Maynooth University, Maynooth, Ireland \\ Geoff Simmons \\ Queen's Management School, Queen's University Belfast, Belfast, UK
}

\begin{abstract}
Purpose - Drawing on the resource-based view of the firm, this article explores the influences of market intelligence on the development of small business marketing capabilities, with reference to specialized marketing capabilities, architectural marketing capabilities and dynamic capabilities.
\end{abstract}

Design/methodology/approach - The conceptual framework and propositions present and interpret the resource-capability complementarity between market intelligence and small business marketing capabilities and outline the relationship between individual capability sets. Findings - Market intelligence is shown to be crucial in the development of small business marketing capabilities and in the implementation of more formalized marketing strategies that allow small businesses to create value for customers and improve their performance. However, the level to which market intelligence is utilized and marketing capabilities are developed is found to be considerably influenced by the small business owner-manager and firm learning. Practical implications - It is imperative that small businesses acknowledge the practical benefits of market intelligence and harness these advantages accordingly. However, ownermanagers must be motivated to encourage the development of more formalized marketing capabilities and act incisively upon the information derived from market intelligence.

Originality/value - Recent research indicates that market intelligence and marketing capabilities can interact to enable a firm to align its resources with the market, by providing customer insights that guide them as to which value-adding activities they should implement. However, extant research in this area remains in its infancy, and very little is known about the adoption processes of market intelligence in small businesses and its role in developing marketing capabilities.

Keywords Market intelligence, Marketing capabilities, Small business marketing, Learning Paper type Conceptual paper 


\section{Introduction}

Market intelligence (MI) presents unprecedented opportunities for businesses in connecting with and creating long-term relationships with customers (Hutchinson et al., 2015). It has therefore been identified as a key factor in businesses achieving competitive advantage in their markets (Erevelles et al., 2016). It also offers small businesses the opportunity to identify market attractiveness, build new value propositions and drive innovation (Del Vecchio et al., 2018). Small businesses are facing increased pressure to utilize formalized MI to differentiate their services and offerings to compete with their larger counterparts that routinely deploy MI (Cacciolatti and Fearne, 2013; Donnelly et al., 2012). Therefore, it is vital that small businesses know how markets will develop, what the future key trends will be and how customer profiles might change. MI informs the answers to these strategic questions and guides market planning and the marketing mix. Consequently, the returns gained from the utilization of formalized MI can be significant, but only if small businesses are willing to integrate the resource and deploy it through their marketing capabilities (Helm et al., 2014).

Formalized MI in this study derives from real-time consumer purchasing and behavioral data that provides insights relevant to a firm's context and supports marketing decision-making (Fan et al., 2015). Dunnhumby, the global leader in customer data science and best known for Tesco Clubcard data management, provide aggregated MI reports that highlight specific intervention points for embedding customer-centric decision-making. This knowledge is essential for small businesses as customers are now better informed than ever and pressure from traditional rivals and discounters continues to increase (Dunnhumby, 2019). MI solutions can inform powerful product and category plans including price, promotion and innovation capabilities. This helps to deliver simple and valuable in-store and online experiences that drive penetration and repeatpurchase rate.

To date, small businesses have generally had limited exposure to such formalized sources of MI (Jocumsen, 2004; O’Connor and Kelly, 2017). However, MI resources are becoming increasingly more accessible to small businesses through funding from governmental bodies and technological aided delivery. Online personalized portals can provide small businesses with more intuitive and customizable dashboards, providing real-time transactional data, customer profiles and segmentations. These interfaces are considerably more comprehensible and manageable and can alleviate the amount of time spent obtaining market insights. Nonetheless, they do not remove the need for continued funding and interpretation assistance 
from supporting bodies. Recent research suggests that small businesses still lack the expertise, time and financial resources to exploit MI (Coleman et al., 2016). Furthermore, they often remain disposed to utilizing existing personal networks that they trust, as opposed to information collected through systematic market research (Jin and Jung, 2016). Thus, in line with Helm et al. (2014), this paper proposes that the challenge for small businesses may no longer be in accessing MI, but in developing well-placed MI utilization and the regular deployment of marketing capabilities.

Extant research into MI utilization in small businesses and its role in developing marketing capabilities remains in its infancy (Hutchinson et al., 2015; Ojiako et al., 2015; Qureshi and Kratzer, 2011). Consequently, calls have been made for further studies to specifically explore how certain marketing capabilities are acquired and improved, through interaction with a firm's marketing-related knowledge resources (Morgan, 2012; Vorhies et al., 2011). A key contention of this paper is that small businesses engaging with more formalized MI require the development of distinct marketing capabilities to exploit opportunities arising and improve their competitive position. Marketing capabilities in small businesses have long been identified as underdeveloped, given their lack of resources, personnel and smaller target markets (Blankson et al., 2006; Gilmore et al., 2001; McCartan-Quinn and Carson, 2003). However, this does not imply that small businesses do not, or are incapable of, conducting marketing. Rather, as the small business literature reiterates, marketing activities exist but are often reactive, unstructured and found to manifest themselves within other firm processes such as logistics, sales and networking (Cacciolatti and Fearne, 2013; Enright et al., 2002).

Morgan et al. (2009) indicate that MI and marketing capabilities can interact to enable a firm to align its resources with the market. MI provides customer insights that guide firms as to which value-adding activities they should undertake, the resources required and how they should be implemented. The resource-based view (RBV) of the firm, as established by Barney (1991), has been extensively utilized as a theoretical base for understanding how certain resources drive better performance and sustained competitive advantage (SCA) (Mac and Evangelista, 2017; Sok et al., 2013). The size of a firm is an important determinant of its resource base, as it proxies their magnitude and the personnel available to utilize them (Cacciolatti and Fearne, 2013; Singh, 2009). All firms face environments that are dynamic, but small businesses have fewer resources to call upon to acclimatize to these uncertainties (Verreynne et al., 2016). Thus, isolating which resources are associated with higher levels of performance is critical (Grimmer et al., 2017). Nonetheless, the assumption explicit in RBV, 
that SCA is achievable through heterogeneous firm resource endowments alone, has been repeatedly questioned (Eisenhardt and Martin, 2000; Newbert, 2007; Priem and Butler, 2001). This has led to the evolution of RBV through the consideration of the role of the organization and capabilities in resource deployments (Barney, 1997; Barney and Wright, 1998). While resources have potential value in achieving improved firm performance, they remain static until they are deployed via a complementary capability (O'Cass and Sok, 2014). Consequently, this study places emphasis on how MI is leveraged and deployed in small businesses and how marketing capabilities are developed during this process.

Accordingly, a conceptual framework and set of research propositions are developed by drawing on the marketing and small business literature. The framework and propositions interpret complex interactions in small businesses between MI, specialized marketing capabilities, architectural marketing capabilities and dynamic capabilities. These marketing capabilities have yet to be given adequate consideration by academic literature in the small business context (Merrilees et al., 2011; Rice et al., 2015). However, they are identified within this paper as critical to the deployment of formalized marketing strategies as they are thought to reside at the frontline of the marketing function (Morgan, 2012). Therefore, developing our understanding of their interactions with MI will be key to the enhancement of small business customer focus and the capacity to compete in volatile markets (Morgan, 2012; Vorhies and Morgan, 2003). The paper now proceeds by discussing the relevant literature to build a theoretical framework. This culminates in a conceptual model that interprets the relationship between MI and small business marketing capabilities. Implications for policy and practice are then discussed, followed by directions for further research.

\section{Theoretical framework}

\section{Small businesses and market intelligence}

MI, while not a new business resource, is a relatively new field of academic inquiry in the context of small business research (Donnelly et al., 2015; O’Connor and Kelly, 2017). MI informs the market research process, providing relevant data to help small businesses address marketing challenges such as market segmentation and product innovation. Indeed, firms that collect and leverage intelligence about their external environment are significantly more likely to make better decisions (Erevelles et al., 2016). Cacciolatti and Fearne (2013) report that small businesses frequently acquiring and utilizing MI exhibit enhanced accuracy when making decisions and respond more effectively to dynamic marketplaces. Despite this, small businesses 
tend not to invest in MI and the marketing function more generally (Donnelly and Simmons, 2013a). This has been attributed to financial deficiencies, their traditional and product-driven nature and the belief that the firm is simply too small to warrant its use (Grimmer et al., 2017; Reijonen and Komppula, 2010; Wee and Chua, 2013).

Donnelly et al. (2012) note that larger firms are often more suited to adopting MI, given their more structured approach to generating, disseminating and responding to MI. Some scholars note that small businesses may not require MI due to their informal marketing processes such as networking ability, intuitive feel for customer needs and closeness to the market (Shaw, 2006). This suggests that informal sources of MI through networking at business conferences, customer engagement and regular meetings with buyers and suppliers are adequate for small businesses to understand their markets. Although these informal information-seeking behaviors are not constraints (Pelham and Wilson, 1996), the counter argument is that more formalized MI is a means of sharpening informal market knowledge with more precise market understanding (Donnelly et al., 2015). For example, formalized MI sources can provide small businesses with detailed performance metrics, customer purchasing habits, shopper profiles and competitor and retailer insights. From this, small businesses can identify who is purchasing their product/s, underserved customer segments and other product categories that specific customers buy. This, in turn, may lead to greater customer value, loyalty and return on investment (Donnelly et al., 2012, 2015).

Didonet et al. (2016) surmise that small businesses engaging with more formalized MI require the development of specific marketing capabilities to exploit new opportunities and improve their competitive position. This presents a significant challenge for small businesses given their propensity for informal market planning based upon their inherent flexibility and intuition. These unique features originate from owner-manager perception of marketing, which Stokes (2000) states is derived from a view that business success can be achieved without formalized marketing planning. However, a negative interpretation of marketing and the resources required to sustain it can prevent the proactive acquisition and utilization of MI (Maes and Sels, 2014; Massiera et al., 2018b). MI may appear to be the antithesis of, or counteract, the intuitive thinking or experience-driven decision-making of owner-managers (O'Connor and Kelly, 2017). Therefore, it is not surprising that owner-managers may be concerned that the implementation of MI could reduce their influence and lead to their intellectual redundancy. As such, MI is often gathered in an ad-hoc and informal manner, which is heavily influenced 
by the motivations and aspirations of the owner-manager (Gilmore et al., 2001; O'Donnell, 2014; Shaw, 2006), and deployed at their discretion (Maes and Sels, 2014).

Conversely, McAfee and Brynjolfsson (2012) suggest that the power of more formalized MI does not remove the need for owner-manager insight or their intuitive approach to "doing business." Rather, the adoption of MI may encourage a small business to be more analytical in their approach to marketing, while complementing the owner-manager's experience and intuition. Pérez-Cabañero et al. (2012) note that small business exposure to MI leads to the development of marketing capabilities that optimize small business flexibility and responsiveness to customer needs. $\mathrm{MI}$, therefore, enhances small business informal market knowledge derived from experience, by giving direction to owner-manager intuition and increasing the level of confidence they have in their innovative product or service proposals (Donnelly et al., 2015).

\section{Small business marketing capabilities}

Marketing capabilities are complex bundles of skills and knowledge, which are utilized to align and deploy available resources in ways that achieve desired outcomes that are valuable to the customer (Morgan, 2012; Morgan et al., 2018). Specialized marketing capabilities refer to functionally focused, marketing mix-related processes, which work in cohesion with market research and the planning processes involved in architectural marketing capabilities (Morgan et al., 2018). Dynamic capabilities foster market-based learning and use the subsequent insights to reconfigure and combine the firm's resources and capabilities to attain improved market effectiveness (Morgan, 2012; Teece et al., 1997). Morgan (2012) indicates that a hierarchy of marketing capabilities exists between specialized, architectural and dynamic capabilities. Indeed, Rice et al. (2015) make the interesting assertion that if dynamic capabilities exist to create, extend and modify low-level resources and capabilities, the evolution of capabilities must occur within some kind of hierarchy (Helfat et al., 2007; Winter, 2003).

In this hierarchical perspective, specialized and architectural marketing capabilities have been identified as low- and mid-level capabilities (also referred to as static by Day, 2011; operational by Helfat et al., 2007 and zero-level and ordinary by Winter, 2003), while dynamic have been identified as higher-level capabilities (also referred to as first-order by Winter, 2003). Establishing a hierarchical integration of marketing capabilities within a firm has been identified as critical for performance advantages as it is difficult for competitors to imitate, thus limiting transferability (Day, 1994; Grewal and Slotegraaf, 2007; Teece et al., 1997; Santos- 
Vijande et al., 2012). Nonetheless, considering the constraints of the small business marketing function, the development and integration of marketing capabilities will vary from the processes implemented in large firms. Therefore, each capability set is discussed further with consideration of the unique small business context.

Specialized marketing capabilities reflect task-specific marketing activities that relate to the classical marketing mix (Morgan et al., 2018; Takata, 2016). They have been identified as particularly important for small businesses as they aid in differentiating a firm's offerings from their competitors (Perreault et al., 2010). All businesses conduct specialized marketing capabilities on some level as every firm must produce a product, price it and distribute it to survive. However, the implementation of an undeveloped marketing mix could be perilous given increasingly competitive markets and the dominance of large competitors. Often, small businesses are found to operate on this functional level, subsequent to their product-orientated and cost-driven nature (Pérez-Cabañero et al., 2012). However, those small businesses willing to refine the deployment of specialized marketing capabilities, facilitated by MI and market planning, may maximize profitability. Indeed, it is thought that through this resourcecapability integration that the marketing mix is better informed and directed toward meeting customers changing demands (Trez and Bins Luce, 2012).

Architectural marketing capabilities are viewed as the planning-related processes involved in selecting objectives and formulating strategies to create distinct and compelling customer value propositions (Morgan, 2012; Vorhies and Morgan, 2003). They are thought to reduce environmental uncertainty by clearly identifying a firm's strengths, weaknesses, markets and competitors (Alpkan et al., 2007). The insights derived from market research and planning provide the coordination needed to ensure that a firm's specialized marketing capabilities are aligned and effectively deployed within the market (Morgan, 2012; Trez and Bins Luce, 2012). However, it has been well documented that small businesses adopt limited architectural marketing capabilities, as they place lower strategic relevance on market planning, preferring a more reactive approach that requires less dedication of time (Alpkan et al., 2007; Donnelly et al., 2015; Santos-Vijande, 2012). However, the deployment of architectural marketing capabilities, cultivated by the deployment of MI, may help to better focus small business resource deployments. Keh et al. (2007) purport that architectural marketing capabilities identify the needs of specifically targeted customer bases and potential new markets. They also enable small businesses to formalize their planning processes, while allowing the firm to 
capitalize upon their inherent flexibility; a significant competitive advantage they hold over their larger competitors (Alpkan et al., 2007).

Specialized and architectural marketing capabilities are important antecedents to the efficiency of a firm's core dynamic capabilities (Takata, 2016). Dynamic capabilities are the means by which firms "integrate, build, and reconfigure internal and external competences to address rapidly changing environments" (Teece et al., 1997, p. 516). The term "dynamic" refers to a firm's capacity to stay abreast of changing markets, while "capabilities" refers to the ability to manipulate and combine resources to respond to changes in the environment (Chirico and Nordqvist, 2010). Various definitions and perspectives of dynamic capabilities have been presented in the literature, often causing confusion for both researchers and practitioners (Kevill et al., 2017; Pavlou and El Sawy, 2011). For example, Hou (2008) suggests that dynamic capabilities derive from four components - sensing capability, adaptive capacity, integrative capability and innovative capability. On the other hand, Rice et al. (2015) propose three alternatives: processual formalization, social integration platforms and information maturity. In accord with Ince and Hahn (2020), we reflect Teece et al.'s (1997) seminal framework, by conceptually exploring the influence of MI on sensing, seizing and reconfiguring. These micro-foundations of dynamic capabilities have been selected as they are suitable components for development in the small business context and are congruent with the utilization of MI.

Dynamic capabilities are significantly more complex than specialized and architectural marketing capabilities. Small businesses are rarely considered as fully dynamic, but those that are tend to present a dynamic culture from their conception (Arend, 2014). Dynamic capabilities do not represent ad-hoc solutions to problems that can be implemented on demand; the approach so often taken by small businesses. Consequently, the literature contends whether small businesses can develop them (Arend, 2014). Hernández-Linares et al. (2020) concede that dynamic capabilities are not easily established in small businesses given their weaker market power and higher vulnerability to environmental changes. Similarly, Macpherson et al. (2015) add that dynamic capability theory assumes a wide range of available firm resources and owner-manager comprehension of resource and capability reconfiguration. However, in most small businesses such capacities are unlikely to be present. Nonetheless, extant theoretical and empirical research still supports the development and utilization of dynamic capabilities in small businesses (Hernández-Linares et al., 2020; Macpherson et al., 2015; Maes and Sels, 2014; Rice et al., 2015). This research suggests that the continuous use of MI enables dynamic 
capabilities to play a critical role in fostering change and creating new value in small businesses (Chirico and Nordqvist, 2010). This is based upon the informational nature of MI, which allows small businesses to deploy market sensing and reconfigure their capabilities accordingly to seize market opportunity. However, this is a learned process through experience, which develops over time. Consequently, the role of learning is proposed in this study as critical to the creation and maintenance of dynamic capabilities and to the full implementation of MI in small businesses.

\section{Small business learning}

Small business learning has become an increasingly significant area of interest for researchers (Altinay et al., 2016; Macpherson and Holt, 2007; Sanzo et al., 2012; Real et al., 2014; Zhang et al., 2006). However, there remains a gap in the literature as to how learning fosters the application of MI and how it may facilitate the development of marketing capabilities in small businesses (Sanzo et al., 2012). Some small businesses will be comfortable with the changes and new processes required to utilize MI and marketing capabilities effectively. However, small businesses such as these are in the minority and tend to be learning-orientated, inherently entrepreneurial and proactive in MI application. Conversely, and in the main, small businesses do not support a learning culture (Reijonen, 2010). This often arises from their small and unskilled personnel base, insufficient time and difficulty in retaining and sharing knowledge within the firm (Sanzo et al., 2012). Given that these deficiencies may inhibit learning, and that learning is critical to MI and marketing capability deployment, it is imperative that the processes associated with learning are prioritized and approached with conviction in these firms (Evangelista and Mac, 2016; Sanzo et al., 2012).

This more cognitive approach to learning has been identified as planned or deliberate learning (Zollo and Winter, 2002). Deliberate learning endorses the value of learning within the firm and the importance of purposeful activities, which create, analyze and transfer knowledge (Evangelista and Mac, 2016; Nembhard and Tucker, 2011). It plays a crucial role in a firm's capacity to adjust to MI and in developing firm knowledge about customers, competitors and markets. Likewise, research suggests that learning processes drive the creation and reconfiguration of marketing capabilities over time (Didonet et al., 2012; Evangelista and Mac, 2016; Real et al., 2014). For that reason, small businesses exhibiting an underdeveloped marketing function must practice learning to understand the processes involved in developing marketing capabilities. However, for learning to be truly effective, it must be spearheaded by the small business owner-manager. Given their dominant role in the firm, it is their 
responsibility to instigate and involve all personnel in formal or informal meetings where MI is explored and knowledge is exchanged. They must also drive and direct a means of evaluating and learning from the outcome of their implemented marketing strategies (Jerez-Gomez et al., 2005). Therefore, this paper affirms that the rate at which learning occurs, MI is deployed and marketing capabilities develop, is dependent upon the small business owner-manager (Nembhard and Tucker, 2011). The learning process and its role in the application of MI and the development of small business marketing capabilities, are further interpreted by the conceptual framework and research propositions as follows.

\section{Conceptual development and propositions}

Fuller (1994) suggests that the higher the quality of marketing capabilities in small businesses, the better their performance. However, the utilization of MI is crucial to the realization of marketing capabilities and thus superior performance in small businesses (Keh et al., 2007). Figure 1 presents a conceptual framework that interprets the complex interactions between MI and specialized marketing capabilities, architectural marketing capabilities and dynamic capabilities in small businesses. Key to the resource-capability interactions presented in the framework is the role played by learning and small business owner-managers. The conceptual framework and propositions provide pertinent theoretical and managerial implications for small business literature, which are discussed further in subsequent sections.

\section{$\underline{\text { Figure 1: Conceptual Framework }}$}

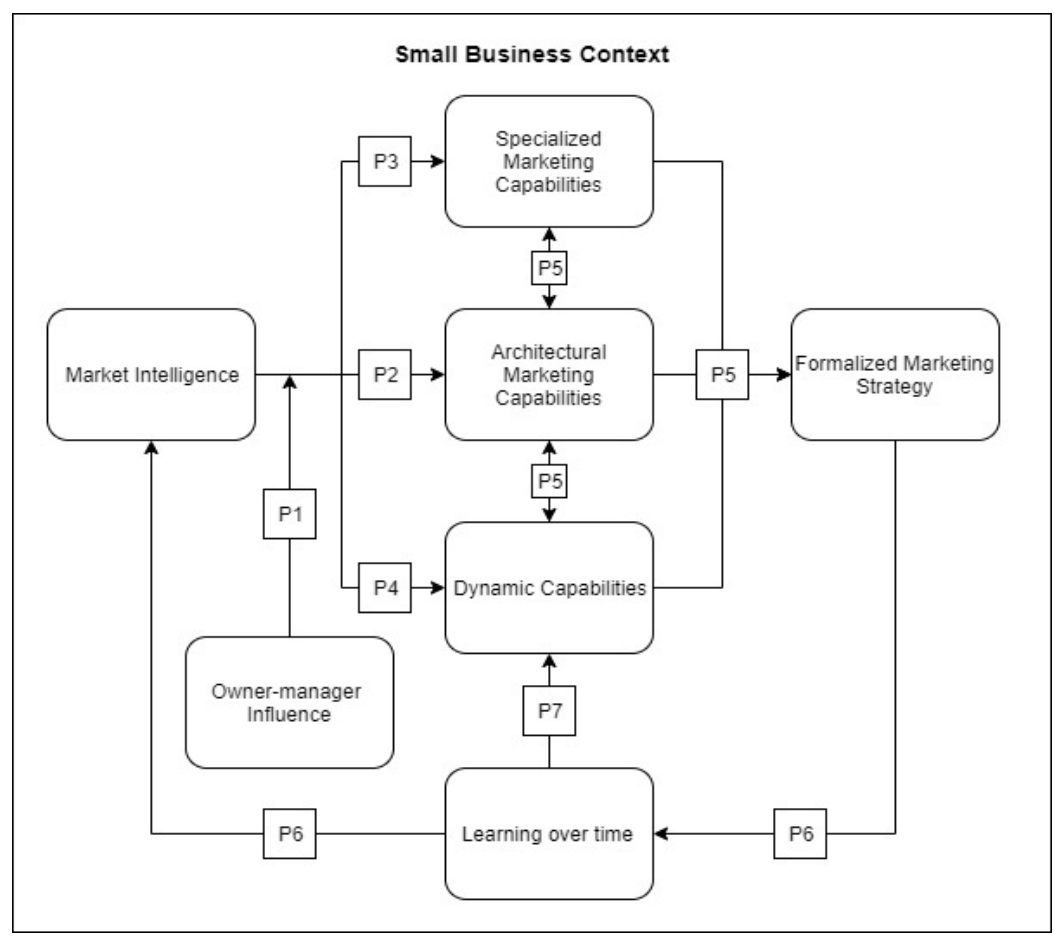


The deployment of MI in small businesses is highly dependent upon owner-manager perception of the resource (Massiera et al., 2018b; Reijonen, 2010) and their perceived self- efficacy in independently dealing with the environment (Donnelly et al., 2012; Kevill et al., 2017; Zhang et al., 2006). Owner-managers with empathy for the value of information, or who possess a proactive approach to marketing, are more likely to engage with MI. Conversely, Coleman et al. (2016) suggest that many owner-managers avoid the utilization of MI due to a lack of technically skilled staff and time to train employees in new areas of expertise. However, the authors also highlight the inertia of some owner-managers toward MI and marketing practices. Massiera et al. (2018b, p. 688) posit that "owner-managers tend to have a subjective, but negative perception of traditional marketing concepts and practices" and "generally perceive the normative, conventional and taken for granted dimensions of marketing principles and practices as useless and unsuitable for their companies." Such perceptions can significantly impede the acquisition and absorption of MI into small businesses and hinder the development of marketing capabilities. However, recent research indicates that MI has the potential to encourage a shift from small business owner-manager dominance toward open-minded engagement (Donnelly et al., 2015). This was evinced by Donnelly and Simmons (2013b), who found that "once their [small business owner-managers] eyes were opened to the power of data, the firms saw immediately how great their disadvantage had been." Hence, this paper argues that small business owner-managers may come to trust MI with increased exposure. Brunetto and Farr-Wharton (2007) indicate that owner-managers experiment with trust, such that, if a first experience is evaluated as positive, they are likely to behave accordingly, initiating further interaction. Therefore, we propose:

\section{P1. Owner-managers influence the level of MI absorption in small businesses}

Architectural marketing capabilities have been identified in the literature as an important constituent of how firms create competitive position (Santos-Vijande et al., 2012). They drive the disciplined decisions as to where the firm will stake its claim in the market, what value it will offer and how this value will be delivered (Day, 2011). This study suggests that these functionalities are significantly enriched by MI as its structured and informational nature provides the relevant insights to improve and ratify decisions relative to customer value and satisfaction (Donnelly et al., 2012; Donnelly and Simmons, 2013a; Hutchinson et al., 2015). Following the acquisition of MI in proactive small businesses, the resource naturally instigates market research, which innately leads to the development of primary market planning processes. Initially, these interactions may not be recognized as the deployment of marketing 
capabilities. However, as firms practice these skills over time, market research and planning become refined and embedded processes within an acknowledged and emerging marketing function, originating from and facilitated by MI.

Lackman et al. (2000) align MI and architectural marketing capabilities by delineating the importance of applying MI during planning activities to reduce market uncertainties and the potential absence of knowledge (Bolisani and Bratianu, 2017). The relationship between MI and architectural marketing capabilities is also supported by Tan and Ahmed (1999), who describe it as a continuum of timely information use, to enlighten marketing decisions and improve market planning, implementation and control. Moreover, given the product-driven nature of small businesses, the literature particularly identifies the important complementary relationship between MI, architectural marketing capabilities and product innovations (Donnelly et al., 2012). This complex resource-capability interaction forms a robust base for successful product launches and deters risk by aligning products with the needs of identified target markets. Therefore, we propose:

$P 2$. MI positively influences the development of architectural marketing capabilities in small businesses.

Without market planning and detailed market segmentation, the implementation of an efficient and effective marketing mix cannot take place. Therefore, this paper proposes that there is no long-term relationship between specialized marketing capabilities and MI. Rather, this relationship is, or should be, facilitated by architectural marketing capabilities to maximize the potential of MI and its benefits. Immediate decisions, relative to the marketing mix, can be implemented from an ad-hoc consultation of MI. However, small businesses may struggle to capitalize upon MI in this manner. Their smaller size may provide flexibility in customer relationships, responsiveness and innovativeness (Moriarty et al., 2008), but on the other hand, it restricts their ability to rapidly modify their operating environments. This is particularly true of those aspects of business that are susceptible to, or dependent upon, external entities. For example, price and promotion are often dictated by large retailers or competitor's behavior. Keh et al. (2007) concede that small businesses are price-takers in the industry, with little ability to shift the price level for specific product categories or to actively change their prices extemporarily. Similarly, adapting products with immediacy generally results in basic modification or parallelization of products already on the market (Keh et al., 2007). Decisions such as these may be difficult to implement on demand and only have a short-term influence 
on performance. Day (2011) has described this as a means of surviving solely in the present and indicates that it may be detrimental in the long run as it does not promote development of future directional strategies.

A more proactive use of MI, based on long-term planning, enables small businesses to prepare to enact strategies and deal with resource restrictions and external dictations. MI allows small businesses to engage in monitoring customer preferences and changing trends, with the objective of implementing a marketing mix that resonates with customers (Keh et al., 2007). Indeed, Donnelly et al. (2012, p. 520) propose that "it is the consideration of these latent needs that creates the potential for radical innovation" and advances new product development and firm performance. Thus, by exercising architectural marketing capabilities to inform the deployment of a firm's marketing mix, small businesses can offer prospective product differentiation to targeted customer segments. Therefore, we propose:

$P 3$. MI positively influences the development of specialized marketing capabilities in small businesses, when facilitated by architectural marketing capabilities.

The feasibility of dynamic capabilities in small businesses has been the subject of debate, given their size, resource constraints and simpler organizational design (Arend, 2014). However, Macpherson et al. (2015) contend that dynamic capabilities can be cultivated in small businesses by integrating external MI resources, garnering knowledge from their networks and capitalizing upon their inherent flexibility to facilitate change. Morgan (2012) suggests that market knowledge is a precondition for the development of dynamic capabilities. Indeed, irrespective of firm size, the literature indicates that the use of novel insights extracted from MI to understand unmet customer needs is thought to enhance a firm's dynamic capability (Erevelles et al., 2016).

The micro-foundations of dynamic capabilities, previously outlined as sensing, seizing and reconfiguring, are individually enhanced by MI. Market sensing activities are positively influenced by MI, so much so, that MI has been identified as a prerequisite to market sensing capability by Foley and Fahy (2004). Any firm utilizing MI is enhancing their ability to sense the market, as the resource can inform them about the external environment and their performance in it. Yet, as Rice et al. (2015) explain, only those firms capable of adequately seizing opportunities, identified in the sensing process, can influence trends or create demand. Exposure to MI can facilitate seizing activities by providing assurance and helping to manage associated risks. Furthermore, MI provides a strong basis upon which the owner-manager can 
confidently present the market potential of new offerings to buyers (Donnelly et al., 2012). To realize opportunities effectively, however, small businesses must transform their resources and capabilities to align with these opportunities. The essence of dynamic capabilities is the firm's ability to reconfigure in ways that meet market demand. These reconfigurations are enriched and sustained by MI as it guides the investment of new external resources and indicates which internal resources should be released or improved (Morgan, 2012). Therefore, we propose:

P4. MI positively influences the development of the dynamic capabilities in small businesses.

Morgan et al. (2012) propose that aligning marketing capabilities has synergistic value-creating effect beyond the contribution of an individual capability. For example, small businesses can leverage architectural marketing capabilities to research new offerings and plan their market position. However, without the deployment of specialized marketing capabilities, this offering will never reach the market. Similarly, firms utilizing both these capabilities can plan and deliver a formalized marketing strategy, but they may not achieve sustained performance. Dynamic capabilities are required to facilitate the reconfiguration of firm resources and capabilities as markets change in order to maintain a competitive position. This capability integration creates causal ambiguity (Fahy and Smithee, 1999). RBV and capabilities literature has attributed this, in part, to the implicit internal mechanisms that are difficult for competitors to diagnose and imitate (Hunt and Morgan, 1996). Indeed, Teece et al. (1997) assert that the underlying significance of the complementarity of capabilities is that it reduces resource deficiencies, reconfigures capabilities and generates formalized marketing strategies that competitors find hard to replicate. Therefore, we propose:

P5. Marketing capability integration facilitates the implementation of formalized marketing strategies in small businesses.

Small businesses that evaluate and learn from the implementation of their formalized marketing strategies create new insights (Sok et al., 2013) and are significantly more likely to reinforce the use of MI. Learning can help small businesses identify areas of improvement that will deliver increased customer value through enhancements to the marketing mix (Anderson and Boocock, 2002). Additionally, learning processes delimit the bounds of existing knowledge relating to the target market and external environment (Karami and Tang, 2019). This understanding precipitates the acquisition of further MI to bridge gaps in firm knowledge. Learning from the resource about the market, but also how best to deploy it within the firm, 
culminates in a perceived value of MI as the small business begins to capitalize upon benefits as they accrue. Learning can thus play a crucial role in a firm's willingness to adopt MI, even in firms were owner-managers hold an internal locus of control. Learning the processes required for a full implementation of MI and acceptance of the changes it drives in firm processes may take time to cultivate. However, with every successful interaction between MI and the firm, its acquisition and utilization are reinforced. Therefore, we propose that:

P6. Learning over time reinforces the acquisition and utilization of MI.

By nature, MI is an informational resource that facilitates firms in learning about their current and future environment regarding customers, competitors and channels. Moreover, small businesses utilizing MI will actively learn the internal processes required to deploy marketing capabilities and leverage MI. These processes eventually become structured and embedded in the firm; however, such processes can lose their value quickly if they support a plan or marketing mix that no longer aligns with market needs or are vulnerable to emulation by competitors (Teece et al., 1997). Therefore, we particularly refer to the centrality of learning in the application of dynamic capabilities and its micro-foundation of reconfiguration. Learning identifies the need to reconfigure out-of-date resources, capabilities and marketing strategies, in order to consolidate and secure competitive positioning in volatile markets. Learning informs and precipitates the refinement and/or creation of new internal processes, which in turn requires further learning to be understood and embedded in the firm. Finally, it should be said that learning in itself must also evolve over time. Choueke and Armstrong (1998) conclude that the establishment of a learning culture within small businesses should be seen as a journey of continuous learning, which adapts as markets change. This is critical as it prevents stagnant organizational learning processes, which too may lose their value. Therefore, we propose:

P7. Learning over time reinforces the development and reconfiguration of marketing capabilities in small businesses.

\section{Discussion}

This study contributes to the recent and growing body of literature pertaining to the latent antecedents of marketing capabilities in small businesses (Merrilees et al., 2011; Qureshi and Kratzer, 2011; Santos-Vijande et al., 2012) by interpreting the crucial role MI plays in their development. In doing so, this study responds to calls by Vorhies et al. (2011) and Morgan (2012) to identify how new market knowledge can be used to improve and reconfigure a firm's capabilities in ways that match the evolving requirements of their marketplace. This paper 
proposes that MI provides small businesses with informed and actionable insights, which incites the development of marketing capabilities. The continuous deployment of these insights allows small businesses to become increasingly more familiar with the marketing capabilities required to maximize the resource, resulting in more developed and integrated marketing capabilities.

This paper supports the RBV literature that highlights the importance of complementarity between resources and capabilities, and it reinforces the premise that a firm's competitive positioning is not reliant on resources alone (Ketchen et al., 2007; O'Cass and Sok, 2014; Penrose, 1959; Sok and O’Cass, 2011; Sok et al., 2016; Srivastava et al., 2001). Rather, it is the bundles of skills that leverage static resources that are critical as they create idiosyncratic and inimitable internal capabilities (Murray et al., 2011; Nenonen et al., 2019; Real et al., 2014). A firm's ability to align MI with complementary marketing capabilities may indicate why some small businesses perform better than others. Informed by Sok and O'Cass (2011) and Sok et al. (2016), we suggest that performance improvements do not rely on how much MI a small business acquires, or how developed a specific capability is, but on the deployment of a resource through a complementary set of capabilities.

This study also supports the literature that refers to the importance of interconnectedness between capability sets (Sok et al., 2013; Morgan, 2012; Teece et al., 1997). Drawing on Nenonen et al. (2019), we contend that while one capability may be necessary in the development of a formalized marketing strategy, it is not sufficient. The outlined propositions in this paper suggest that small businesses possessing one capability, but lacking in others, are at a disadvantage to those who endeavor to develop an integrated hierarchy of marketing capabilities. The propositions delineate the important reciprocal relationship between specialized and architectural marketing capabilities, which in turn, underpins the development of dynamic capabilities. Indeed, Hine et al. (2014, p. 1302) explain that "higher-order capabilities have the greatest impact on the strategy of the firm, yet still rely on successful management of lower-order capabilities for the firm to function effectively." Thus, we conclude that small businesses that attain this are best placed to deploy an inimitable, formalized marketing strategy.

The issue of formalized marketing practices is addressed by Donnelly et al. (2015) in their study of formal market intelligence versus informal small business marketing planning. We support the authors' assertion that MI simultaneously fosters the introduction of formalized 
planning in small businesses, while complementing the informal and flexible manner of conducting business (Donnelly et al., 2015). We extend this by proposing that MI can sustain the formalization of marketing strategies in small businesses. However, the level to which this formalization occurs is again reliant on owner-manager perceptions of marketing and marketing resources (Reijonen, 2010). Indeed, many owner-managers deem firm success as obtainable without the use of formalized marketing processes (Donnelly et al., 2012). Accordingly, these small business owner-managers may consciously ignore the potential role of MI in their firm and its latent benefits (Maes and Sels, 2014). This behavior is very much consistent with the often short-term, nonstrategic focus of small businesses, which constrains marketing capabilities and MI-seeking behaviors (Fuellhart and Glasmier, 2003). Consequently, we suggest that some small businesses may fail to absorb MI and neglect the development of their marketing capabilities.

Small businesses that endeavor, but struggle to utilize MI, may find that their resource deficiencies directly affect their ability to understand and deploy MI (Donnelly and Simmons, 2013a). In this regard, the RBV has been identified as representing a "conundrum" for small businesses (O'Connor and Kelly, 2017). Thus, we highlight the importance of deliberate learning as a response to these firm constraints as learning emphasizes the need to seize new opportunities and the quality of resources and capabilities necessary to realize these opportunities (Gnizy et al., 2014). Such learning processes will be idiosyncratic to each business and may also require significantly more direction and commitment in some firms than in others. However, learning remains a critical component, even in firms that are comfortable with the proactive use of MI. This paper contends that learning at any level of MI deployment is imperative as it aids in the integration of marketing capabilities, the development of higherlevel capabilities and acts as a catalyst for capability reconfiguration in dynamic markets.

\section{Practice and policy implications}

In this new age of MI, small businesses are being presented with a huge opportunity to capitalize upon insights to build sustainable value propositions for customers (Del Vechicco et al., 2018). Integral to this is how new forms of MI can be accessed and integrated into the dayto-day activities of small businesses. Access to more intuitive and comprehensible data formats is now being opened up to small businesses (Donnelly et al., 2012; Massiera et al., 2018b) and is often provided in conjunction with financial and interpretive support from governmental subsidization (Cacciolatti and Fearne, 2013). However, this research suggests that small 
business owner-managers bear great responsibility in enacting the changes required to effectively deploy MI. They must be motivated to instill and reiterate the marketing processes required for its effective utilization and drive increased learning. Small businesses can no longer afford to remain skeptical of, or neglect, the benefits of MI and marketing capabilities (Donnelly et al., 2012; Massiera et al., 2018b; Ojiako et al., 2015). As McAfee (2013) predicts, small businesses relying on intuition and "gut" instinct will be replaced by those firms monopolizing MI to make more effective marketing decisions. This could have a significant effect on the business landscape (Donnelly and Simmons, 2013b), given the contribution small businesses make to revenue and productivity levels in the United Kingdom and further afield (Economic and Social Research Centre, 2016).

A manner by which marketing capabilities can be monitored in small businesses may be of interest to owner-managers as a means of managing their resource acquisition and utilization (Hine et al., 2014). However, it will also be of interest to governmental bodies that provide the funding to underwrite small business access to MI resources and associated interpretative support. Marketing capabilities can be better understood as part of a hierarchy (Hine et al., 2014; Massiera et al., 2018a; Morgan, 2012); indeed, this graduated classification of capabilities can indicate the extent of and need for development of capabilities within a firm (Hine et al., 2014). The marketing capability hierarchy, discussed in this study, consisting of low-, medium- and high-level capabilities enables funding bodies involved in the subsidy of MI to decipher the measure and application of marketing capability within their client firms. This enables them to identify capability gaps, those firms requiring planned or impromptu support and the type of guidance or training required. They should also be able to deduce which firms are neglectful in their use of MI, or are erroneous in their approach, given a consequent lack of change in their marketing capability post MI provision. This realization is critical. Cacciolatti and Fearne (2013) refer to limited governmental resources held by supporting bodies, making them obliged to find a delicate balance between supporting lethargic firms and the efficient use of taxpayer's money. Therefore, specific training programs that focus on changing owner-manager marketing perceptions and the importance of learning appear to be crucial. In turn, small business owner-managers must be willing to sacrifice time from daily operations to participate in training. This paper concludes that it is a process of dual responsibility between owner-managers and funding bodies to help small businesses utilize MI to their maximum potential. They must work together to create marketing approaches that are customized, pragmatic and applicable in their markets. 


\section{Directions for future research}

The conceptual framework illustrates that MI shapes the development of small business marketing capabilities and represents a resource-capability complementarity. It also speaks to the role of the owner-manager in MI absorption and the need for a commitment to learning in the developmental process of marketing capabilities. The propositions, however, stem from marketing and small business literature; thus, they need to be verified.

Future empirical research concentrating on the development of marketing capabilities and their potential antecedents has considerable promise. Subsequent studies may wish to explore the compatibility of different formats of MI on marketing capabilities within the small business context. However, the impact of integrating data sources, to provide a holistic view of the market, has recently become of interest, as most existing studies investigate the effects of only one data type (Donnelly and Simmons, 2013a, b; Fan et al., 2015; O’Connor and Kelly, 2017). Given the influence of the owner-manager in small businesses, it may also be of interest to devise a classification of owner-managers based on their response and interaction with MI.

This will give guidance to policymakers as to which firms effectively utilize MI and which may need further support. A greater focus on why some small businesses can implement more complex, higher-level capabilities, while others cannot, is also required. Studies in this field may look to investigate the deep complexities of marketing capabilities and barriers to their development in small businesses. Wang and Ahmed (2007) support the qualitative investigation of this, particularly in the case of dynamic capabilities, to capture their tacit and subtle nature (Björk et al., 2010). A longitudinal and qualitative approach has also been acknowledged as a suitable method of engagement with small business owner-managers (Tregear, 2003). The qualitative consideration of personal motivations, concerns and characteristics is thought to be imperative in understanding how the developmental processes of marketing capabilities are realized by owner-managers (Maxwell, 2005).

\section{References}

Alpkan, L., Yilmaz, C. and Kaya, H. (2007) "Market orientation and planning flexibility in SMEs: Performance implications and an empirical investigation", International Small Business Journal, Vol. 25 No. 2, pp. 152-172.

Altinay, L., Madanoglu, M., De Vita, G., Arasli, H. and Ekinci, Y. (2016), “The interface between organizational learning capability, entrepreneurial orientation, and SME growth", Journal of Small Business Management, Vol. 54 No. 3, pp. 871-891. 
Anderson, V. and Boocock, G. (2002), "Small firms and internationalisation: learning to manage and managing to learn", Human Resource Management Journal, Vol. 12 No. 3, pp. 5-24.

Arend, R.J. (2014), "Entrepreneurship and dynamic capabilities: how firm age and size affect the "capability enhancement-SME performance' relationship”, Small Business Economics, Vol. 42 No. 1, pp. 33-57.

Assadinia, S., Kadile, V., Gölgeci, I. and Boso, N. (2019), "The effects of learning orientation and marketing programme planning on export performance: Paradoxical moderating role of psychic distance", International Small Business Journal, Vol. 37 No. 5, pp. 1-27.

Barney, J.B. (1991), "Firm resources and sustained competitive advantage", Journal of management, Vol. 17 No.1, pp. 99-120.

Barney, J.B. and Wright, P.M. (1998), "On becoming a strategic partner: The role of human resources in gaining competitive advantage”, Human Resources Management, Vol. 37 No. 1, pp. 31-46.

Barney, J.B. (1997), Gaining and sustaining competitive advantage, Addison-Wesley Publishing Company Don Mills, ON.

Björk, J., Boccardelli, P. and Magnusson, M. (2010), "Ideation capabilities for continuous innovation", Creativity and innovation management, Vol. 19 No. 4, pp. 385-396.

Blankson, C., Motwani, J.G. and Levenburg, N.M. (2006), "Understanding the patterns of market orientation among small businesses", Marketing Intelligence \& Planning, Vol. 24 No. 6, pp. 572-590.

Bolisani, E. and Bratianu, C. (2017), "Knowledge strategy planning: an integrated approach to manage uncertainty, turbulence, and dynamics", Journal of Knowledge Management, Vol. 21 No. 2, pp. 233253.

Brunetto, Y. and Farr-Wharton, R. (2007), "The moderating role of trust in SME owner/managers' decisionmaking about collaboration”, Journal of Small Business Management, Vol. 45 No. 3, pp. 362-387.

Cacciolatti, L.A. and Fearne, A. (2013), "Marketing intelligence in SMEs: implications for the industry and policy makers", Marketing Intelligence \& Planning, Vol. 31 No. 1, pp. 4-26.

Chirico, F. and Nordqvist, M. (2010), "Dynamic capabilities and trans-generational value creation in family firms: The role of organizational culture", International Small Business Journal, Vol. 28 No. 5, pp. 487-504.

Choueke, R. and Armstrong, R. (1998), "The learning organisation in small and medium-sized enterprises: A destination or a journey?", International Journal of Entrepreneurial Behavior \& Research, Vol. 4 No. 2, pp. 129-140.

Coleman, S., Göb, R., Manco, G., Pievatolo, A., Tort-Martorell, X. and Reis, M.S. (2016), "How can SMEs benefit from big data? Challenges and a path forward", Quality and Reliability Engineering International, Vol. 32 No. 6, pp. 2151-2164.

Day, G.S. (1994), "The capabilities of market-driven organizations", Journal of marketing, Vol. 58 No. 4 , pp. 37-52.

Day, G.S. (2011), “Closing the marketing capabilities gap”, Journal of marketing, Vol. 75 No. 4, pp. 183195. 
Del Vecchio, P., Mele, G., Ndou, V. and Secundo, G. (2018), “Creating value from social big data: Implications for smart tourism destinations”, Information Processing \& Management, Vol. 54 No. 5, pp. $847-860$.

Didonet, S., Simmons, G., Díaz-Villavicencio, G. and Palmer, M. (2012), “The relationship between small business market orientation and environmental uncertainty", Marketing Intelligence \& Planning, Vol. 30 No. 7, pp. 757-779.

Didonet, S., Simmons, G., Díaz-Villavicencio, G. and Palmer, M. (2016), "Market Orientation's BoundarySpanning Role to Support Innovation in SMEs", Journal of Small Business Management, Vol. 54, pp. 216-233.

Donnelly, C. and Simmons, G. (2013a), "Small Businesses Need Big Data Too", Harvard Business Review.

Donnelly, C. and Simmons, G. (2013b), "Is There Hope for Small business, the Have-Nots in the World of Big Data?", Harvard Business Review.

Donnelly, C., Simmons, G., Armstrong, G. and Fearne, A. (2012), "Marketing planning and digital customer loyalty data in small business", Marketing Intelligence \& Planning, Vol. 30 No. 5, pp. 515-534.

Donnelly, C., Simmons, G., Armstrong, G. and Fearne, A. (2015), "Digital loyalty card 'big data' and small business marketing: Formal versus informal or complementary?", International Small Business Journal, Vol. 33 No. 4, pp. 422-442.

Dunnhumy (2019), "Category Management: Focus on What's Right for your Customer", available at: https://www.dunnhumby.com/sites/default/files/brochures/Category_Management_brochure_web.pdf (accessed 4th November 2019).

Economic and Social Research Centre (2016), "Boosting UK productivity with SME growth", available at: https://esrc.ukri.org/files/news-events-and-publications/evidence-briefings/boosting-uk-productivitywith-sme-growth/ (accessed 26 $6^{\text {th }}$ August 2019).

Eisenhardt, K.M. and Martin, J.A. (2000), "Dynamic capabilities: what are they?”, Strategic Management Journal, Vol. 21 No. 10-11, pp. 1105-1121.

Enright, M., Copley, P., Deacon, J., Carson, D., McAuley, A. and Gilmore, A. co-ordinated by David Carson. (2002), "Contextual Marketing: Marketing in Practice is Different to much of the Textbook Theory?", Academy of Marketing Special Interest Group on the Marketing/Entrepreneurship Interface, Oxford Brookes University Business School, January.

Erevelles. S., Fukawa, N. and Swayne, L. (2016), "Big Data consumer analytics and the transformation of marketing", Journal of Business Research, Vol. 69 No. 2, pp. 897-904.

Evangelista, F. and Mac, L. (2016), "The influence of experience and deliberate learning on SME export performance", International Journal of Entrepreneurial Behavior \& Research, Vol. 22 No. 6, pp. 860-879.

Fahy, J. and Smithee, A. (1999), "Strategic marketing and the resource based view of the firm", Academy of Marketing Science Review, Vol. 10 No. 1, pp.1-21.

Fan, S., Lau, R.Y. and Zhao, J.L. (2015), "Demystifying big data analytics for business intelligence through the lens of marketing mix." Big Data Research, Vol. 2 No. 1, pp. 28-32.

Foley, A. and Fahy, J. (2004), "Towards a further understanding of the development of market orientation in the firm: a conceptual framework based on the market-sensing capability", Journal of strategic marketing, Vol. 12 No. 4, pp. 219-230. 
Fuellhart, K.G. and Glasmeier, A.K. (2003), “Acquisition, assessment and use of business information by small-and medium-sized businesses: a demand perspective", Entrepreneurship \& Regional Development, Vol. 15 No. 3, pp. 229-252.

Fuller, P.B. (1994), “Assessing marketing in small and medium-sized enterprises", European Journal of Marketing, Vol. 28 No. 12, pp. 34-49.

Gilmore, A., Carson, D. and Grant, K. (2001). "SME marketing in practice", Marketing Intelligence \& Planning, Vol. 19 No. 1, pp. 6-11.

Glazer, R. (1991), "Marketing in an information-intensive environment: Strategic implications of knowledge as an asset", Journal of Marketing, Vol. 55 No. 4, pp. 1-19.

Gnizy I.E, Baker, W. and Grinstein, A. (2014), "Proactive learning culture: A dynamic capability and key success factor for SMEs entering foreign markets", International Marketing Review, Vol. 31 No. 5, pp. 477-505.

Grewal, R. and Slotegraaf, R.J. (2007), "Embeddedness of organizational capabilities", Decision Sciences, Vol. 38 No. 3, pp. 451-488.

Grimmer, L., Miles, M.P., Byrom, J. and Grimmer, M. (2017), "The impact of resources and strategic orientation on small retail firm performance", Journal of Small Business Management, Vol. 55, pp. 726.

Helfat, C.E., Finkelstein, S., Mitchell, W., Peteraf, M., Singh, H., Teece, D. and Winter, S.G. (2007), Dynamic capabilities: Understanding strategic change in organizations, Blackwell, Malden, MA.

Helm, R., Krinner, S. and Schmalfuß, M. (2014), “Conceptualization and integration of marketing intelligence: The case of an industrial manufacturer", Journal of Business-to-Business Marketing, Vol. 21 No. 4, pp. 237-255.

Hernández-Linares, R., Kellermanns, F.W. and López-Fernández, M.C. (2020), "Dynamic capabilities and SME performance: The moderating effect of market orientation", Journal of Small Business Management, DOI: $10.1111 /$ jsbm.12474

Hine, D., Parker, R., Pregelj, L. and Verreynne, M.L. (2014), "Deconstructing and reconstructing the capability hierarchy", Industrial and Corporate Change, Vol. 23 No. 5, pp. 1299-1325.

Hooley, G., Fahy, J., Cox, T., Beracs, J., Fonfara, K. and Snoj, B. (1999), "Marketing capabilities and firm performance: a hierarchical model", Journal of Market-focused Management, Vol. 4 No. 3, pp. 259278.

Hou, J.J. (2008), "Toward a research model of market orientation and dynamic capabilities", Social Behavior and Personality: an international journal, Vol. 36 No. 9, pp. 1251-1268.

Hunt, S.D. and Morgan, R.M. (1996), "The resource-advantage theory of competition: dynamics, path dependencies, and evolutionary dimensions", Journal of Marketing, Vol 60 No. 4, pp. 107-114.

Hutchinson, K., Donnell, L.V., Gilmore, A. and Reid, A. (2015), "Loyalty card adoption in SME retailers: the impact upon marketing management", European Journal of Marketing, Vol. 49 No. 3/4, pp. 467-490. 
Ince, I. and Hahn, R. (2020), "How dynamic capabilities facilitate the survivability of social enterprises: A qualitative analysis of sensing and seizing capacities", Journal of Small Business Management, DOI: $10.1111 /$ jsbm. 12487

Jerez-Gomez, P., Cespedes-Lorente, J. and Valle-Cabrera, R. (2005), "Organizational learning capability: a proposal of measurement”, Journal of Business Research, Vol. 58 No. 6, pp. 715-725.

Jin, B. and Jung, S. (2016), "Toward a deeper understanding of the roles of personal and business networks and market knowledge in SMEs' international performance", Journal of Small Business and Enterprise Development, Vol. 23 No. 3, pp. 812-830.

Jocumsen, G. (2004), "How do small business managers make strategic marketing decisions? A model of process", European journal of marketing, Vol. 38 No. 5/6, pp. 659-674.

Karami, M. and Tang, J. (2019), "Entrepreneurial orientation and SME international performance: The mediating role of networking capability and experiential learning", International Small Business Journal, Vol. 37 No. 2, pp. 105-124.

Keh, H.T., Nguyen, T.T.M. and Ng, H.P. (2007), "The effects of entrepreneurial orientation and marketing information on the performance of SMEs", Journal of business venturing, Vol. 22 No. 4, pp. 592-611.

Ketchen, D.J., Hult, G.T.M. and Slater, S.F. (2007), "Toward greater understanding of market orientation and the resource-based view”, Strategic management journal, Vol. 28 No. 9, pp. 961-964.

Kevill, A., Trehan, K. and Easterby-Smith, M. (2017), "Perceiving 'capability' within dynamic capabilities: The role of owner-manager self-efficacy", International Small Business Journal, Vol. 35 No. 8, pp. 883-902.

Lackman, C., Saban, K. and Lanasa, J. (2000), "The contribution of market intelligence to tactical and strategic business decisions", Marketing Intelligence \& Planning, Vol 18 No. 1, pp. 6-9.

Mac, L. and Evangelista, F. (2017), "Transforming learning into export performance by Chinese firms", Asia Pacific Business Review, Vol. 23 No. 4, pp. 493-508.

Macpherson, A. and Holt, R. (2007), "Knowledge, learning and small firm growth: a systematic review of the evidence", Research policy, Vol. 36 No. 2, pp. 172-192.

Macpherson, A., Herbane, B. and Jones, O. (2015), "Developing dynamic capabilities through resource accretion: expanding the entrepreneurial solution space", Entrepreneurship \& Regional Development, Vol. 27 No. 5-6, pp. 259-291.

Maes, J. and Sels, L. (2014), "SMEs' radical product innovation: The role of internally and externally oriented knowledge capabilities", Journal of Small Business Management, Vol. 52 No. 1, pp. 141163.

Massiera, P., Gilmore, A. and Sellami, M. (2018b), "Marketing illegitimacy within SMEs: learning triggers and influence on marketing communications", Journal of Strategic Marketing, Vol. 26 No. 8, pp. 688701.

Massiera, P., Trinchera, L. and Russolillo, G. (2018a), "Evaluating the presence of marketing capabilities: A multidimensional, hierarchical index", Recherche et Applications en Marketing (English Edition) Vol. 33 No. 1, pp. 30-52. 
Maxwell, J.A. (2005), Qualitative Research Design: An Interactive Approach, Sage Publications, Thousand Oaks, CA.

McAfee, A. (2013), "Big Data's Biggest Challenge? Convincing People NOT to Trust Their Judgement", Harvard Business Review.

McAfee, A. and Brynjolfsson, E. (2012), "Big data: the management revolution”, Harvard Business Review.

McCartan-Quinn, D. and Carson, D. (2003), "Issues which impact upon marketing in the small business", Small Business Economics, Vol. 21 No. 2, pp. 201-213.

Merrilees, B., Rundle-Thiele, S. and Lye, A. (2011), "Marketing capabilities: Antecedents and implications for B2B SME performance", Industrial Marketing Management, Vol. 40 No. 3, pp. 368-375.

Morgan, N.A. (2012), "Marketing and business performance", Journal of the Academy of Marketing Science, Vol. 40 No. 1, pp. 102-119.

Morgan, N.A., Feng, H. and Whitler, K.A. (2018), "Marketing capabilities in international marketing”, Journal of International Marketing, Vol. 26 No. 1, pp. 61-95.

Morgan, N.A., Katsikeas, C.S. and Vorhies, D.W. (2012), "Export marketing strategy implementation, export marketing capabilities, and export venture performance", Journal of the Academy of Marketing Science, Vol. 40 No. 2, pp. 271-289.

Morgan, N.A., Vorhies, D.W. and Mason, C.H. (2009), "Market orientation, marketing capabilities, and firm performance", Strategic Management Journal, Vol. 30 No. 8, pp. 909-920.

Moriarty, J., Jones, R., Rowley, J. and Kupiec-Teahan, B. (2008), "Marketing in small hotels: a qualitative study", Marketing Intelligence \& Planning, Vol. 26 No. 3, pp. 293-315.

Murray, J.Y., Gao, G.Y. and Kotabe, M. (2011), "Market orientation and performance of export ventures: the process through marketing capabilities and competitive advantages", Journal of the Academy of Marketing Science, Vol. 39 No. 2, pp. 252-269.

Nembhard, I.M. and Tucker, A.L. (2011), "Deliberate learning to improve performance in dynamic service settings: Evidence from hospital intensive care units", Organization Science, Vol. 22 No. 4, pp. $907-$ 922.

Nenonen, S., Storbacka, K. and Windahl, C. (2019), "Capabilities for market-shaping: triggering and facilitating increased value creation", Journal of the Academy of Marketing Science, Vol. 47 No. 4, pp. $1-23$.

Newbert, S.L. (2007), "Empirical research on the resource-based view of the firm: an assessment and suggestions for future research", Strategic Management Journal, Vol. 28 No. 2, pp. 121-146.

O'Cass, A. and Sok, P. (2014), "The role of intellectual resources, product innovation capability, reputational resources and marketing capability combinations in firm growth", International Small Business Journal, Vol. 32 No. 8, pp. 996-1018. 
O'Connor, C. and Kelly, S. (2017), "Facilitating knowledge management through filtered big data: SME competitiveness in an agri-food sector", Journal of Knowledge Management, Vol. 21 No.1, pp. 156179.

O'Donnell, A. (2014), "The contribution of networking to small business marketing", Journal of Small Business Management, Vol. 52 No.1, pp.164-187.

Ojiako, U., Chipulu, M., Karatas-Ozkan, M., Siao, M.J. and Maguire, S. (2015), "Intelligence management opportunities for SMEs", Journal of Small Business and Enterprise Development, Vol. 22 No. 4, pp. 698-715.

Pavlou, P.A. and El Sawy, O.A. (2011), "Understanding the elusive black box of dynamic capabilities”, Decision sciences, Vol. 42 No. 1, pp. 239-273.

Pelham, A.M. and Wilson, D.T. (1996), "Longitudinal study of the impact of market structure, firm structure, strategy, and market orientation culture on dimensions of small firm performance", Journal of the Academy of Marketing Science, Vol. 24 No. 1, pp. 27-43.

Penrose, E. (1959). The theory of the growth of the firm, John Wiley \& Sons, New York, NY.

Pérez-Cabañero, C., González-Cruz, T. and Cruz-Ros, S. (2012), "Do family SME managers value marketing capabilities' contribution to firm performance?", Marketing Intelligence \& Planning, Vol. 30 No. 2, pp.116-142.

Perreault, W.D., Cannon, J. and McCarthy, E.J. (2010), Essentials of marketing: A marketing strategy planning approach, 12th ed., McGraw-Hill/Irwin, Boston, MA.

Priem, R.L. and Butler J.E. (2001), "Is the resource-based "view" a useful perspective for strategic management research?", Academy of Management Review, Vol. 26 No. 1, pp. 22-40.

Qureshi, S. and Kratzer, J. (2011), "An investigation of antecedents and outcomes of marketing capabilities in entrepreneurial firms: an empirical study of small technology-based firms in Germany", Journal of Small Business \& Entrepreneurship, Vol. 24, No. 1, pp. 49-66.

Real, J.C., Roldán, J.L. and Leal, A. (2014), "From entrepreneurial orientation and learning orientation to business performance: analysing the mediating role of organizational learning and the moderating effects of organizational size", British Journal of Management, Vol. 25 No. 2, pp. 186-208.

Reijonen, H. (2010), “Do all SMEs practise same kind of marketing?", Journal of Small Business and Enterprise Development, Vol. 17 No. 2, pp. 279-293.

Reijonen, H. and Komppula, R. (2010), "The adoption of market orientation in SMEs: required capabilities and relation to success" Journal of Strategic Marketing, Vol. 18 No 1, pp. 19-37.

Rice, J., Liao, T.S., Galvin, P. and Martin, N. (2015), “A configuration-based approach to integrating dynamic capabilities and market transformation in small and medium-sized enterprises to achieve firm performance", International Small Business Journal, Vol. 33 No. 3, pp. 231-253. 
Santos-Vijande, L., Sanzo-Pérez, M., Trespalacios Gutiérrez, J. and Rodríguez, N. (2012), "Marketing capabilities development in small and medium enterprises: implications for performance" Journal of Centrum Cathedra: The Business and Economics Research Journal, Vol. 5 No. 1, pp. 24-42.

Sanzo, M.J., Santos, M.L., García, N. and Trespalacios, J.A. (2012), "Trust as a moderator of the relationship between organizational learning and marketing capabilities: Evidence from Spanish SMEs", International Small Business Journal, Vol. 30, No. 6, pp. 700-726.

Shaw, E. (2006), "Small business networking: An insight into contents and motivating factors", International Small Business Journal, Vol. 24 No. 1, pp. 5-29.

Singh, D.A. (2009), "Export performance of emerging market firms", International Business Review, Vol. 18 No 4, pp. 321-330.

Sok, P., O'Cass, A. and Miles, M.P. (2016), “The performance advantages for SMEs of product innovation and marketing resource-capability complementarity in emerging economies", Journal of Small Business Management, Vol. 54 No. 3, pp. 805-826.

Sok, P., O'Cass, A. and Sok, K.M. (2013), “Achieving superior SME performance: Overarching role of marketing, innovation, and learning capabilities" Australasian Marketing Journal, Vol. 21 No. 3, pp. 161-167.

Sok, P. and O'Cass, A. (2011), “Achieving superior innovation-based performance outcomes in SMEs through innovation resource-capability complementarity. Industrial Marketing Management, Vol. 40 No. 8, pp. 1285-1293.

Srivastava, R.K., Fahey, L. and Christensen, H.K. (2001), “The resource-based view and marketing: The role of market-based assets in gaining competitive advantage”, Journal of Management, Vol. 27 No. 6, pp. $777-802$.

Stokes, D. (2000). "Putting entrepreneurship into marketing: the processes of entrepreneurial marketing", Journal of Research in Marketing and Entrepreneurship, Vol. 2 No. 1, pp. 1-16.

Takata, H. (2016), "Effects of industry forces, market orientation, and marketing capabilities on business performance: An empirical analysis of Japanese manufacturers from 2009 to 2011", Journal of Business Research, Vol. 69 No. 12, pp. 5611-5619.

Tan, T.W. and Ahmed, Z.U. (1999), "Managing market intelligence: an Asian marketing research perspective", Marketing Intelligence \& Planning, Vol. 17 No. 6, pp. 298-306.

Teece, D.J., Pisano, G. and Shuen, A. (1997), "Dynamic capabilities and strategic management", Strategic Management Journal, Vol. 18 No. 7, pp. 509-533.

Tregear, A. (2003), "Market orientation and the craftsperson", European Journal of Marketing, Vol. 37 No. 11/12, pp. 1621-1635.

Trez, G. and Bins Luce, F. (2012), "Organizational structure and specialized marketing capabilities in SMEs”, Marketing Intelligence \& Planning, Vol. 30 No. 2, pp. 143-164.

Verreynne, M.L., Meyer, D. and Liesch, P. (2016), "Beyond the formal-informal dichotomy of small business strategy-making in stable and dynamic environments", Journal of Small Business Management, Vol. 54 No. 2, pp. 420-444. 
Vorhies, D.W. and Morgan, N.A. (2003), "A configuration theory assessment of marketing organization fit with business strategy and its relationship with marketing performance", Journal of Marketing, Vol. 67 No. 1, pp. 100-115.

Vorhies, D.W., Orr, L.M. and Bush, V.D. (2011), "Improving customer-focused marketing capabilities and firm financial performance via marketing exploration and exploitation", Journal of the Academy of Marketing Science, Vol. 39 No. 5, pp. 736-756.

Wang, C.L. and Ahmed, P.K. (2007), "Dynamic capabilities: A review and research agenda", International Journal of Management Reviews, Vol. 9 No. 1, pp. 31-51.

Wee, J. and Chua, A. (2013), "The peculiarities of knowledge management processes in SMEs: the case of Singapore", Journal of Knowledge Management, Vol. 17 No. 6, pp. 958-972.

Winter, S.G. (2003), "Understanding dynamic capabilities”, Strategic Management Journal Vol. 24 No. 10, pp. 991-995.

Zhang, M., Macpherson, A. and Jones, O. (2006), "Conceptualizing the learning process in SMEs: improving innovation through external orientation", International Small Business Journal, Vol. 24 No.3, pp. 299-323.

Zollo, M. and Winter, S.G. (2002), "Deliberate learning and the evolution of dynamic capabilities", Organizational Science, Vol 13 No. 3, pp. 339-351.

\section{Further reading}

Assadinia, S., Kadile, V., G€olgeci, I. and Boso, N. (2019), “The effects of learning orientation and marketing programme planning on export performance: paradoxical moderating role of psychic distance”, International Small Business Journal, Vol. 37 No. 5, pp. 1-27.

Glazer, R. (1991), "Marketing in an information-intensive environment: strategic implications of knowledge as an asset", Journal of Marketing, Vol. 55 No. 4, pp. 1-19.

Hooley, G., Fahy, J., Cox, T., Beracs, J., Fonfara, K. and Snoj, B. (1999), "Marketing capabilities and firm performance: a hierarchical model", Journal of Market-Focused Management, Vol. 4 No. 3, pp. 259-278.

\section{Corresponding author}

Grace Carson can be contacted at: gcarson07@qub.ac.uk 